MODELLING

WHICH

FUTURE?

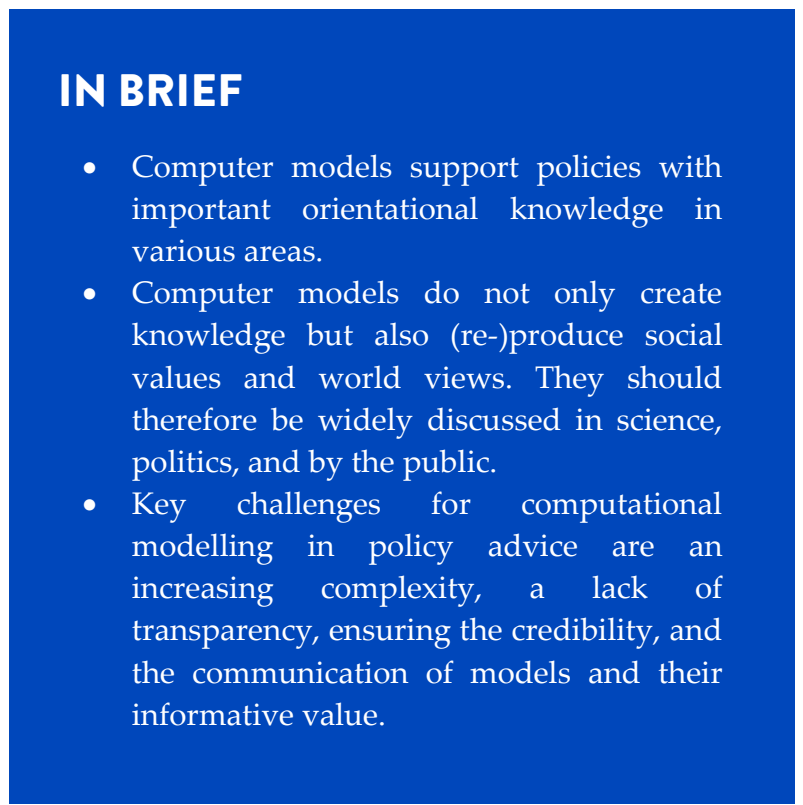

\section{WHAT IS IT ABOUT?}

Computer models are increasingly applied in various areas, from academia and industry to political decisionmaking. In Austria, two recent examples illustrate how crucial models are for informing decision-making and hence also influence citizens' everyday life: the planned use of an algorithm by the Austrian Public Employment Service (AMS; see ITA Dossier No. 43) and the prognoses regarding the COVID-19 pandemic (since the beginning of 2020).

Using computer models is closely linked to efforts for evidence-based policy-making. Against the background of a multitude of complex and socially controversial topics such as energy transition, international trade agreements or nanomaterials risks, modelling becomes increasingly prevalent and prominent.
The constant progress in information and communication technologies (e.g. more powerful hardware) facilitates the increase in modelling applications. New models are continuously developed (e.g. environmental impact modelling in macroeconomic trade analysis or dynamic probabilistic material flow models for nanomaterials). Individual models are often combined into comprehensive modelling frameworks to address better the complexity of political and societal challenges and realities. For example, energy system models may not only focus on the energy system but also integrate transport, agriculture, forestry, and general land use.

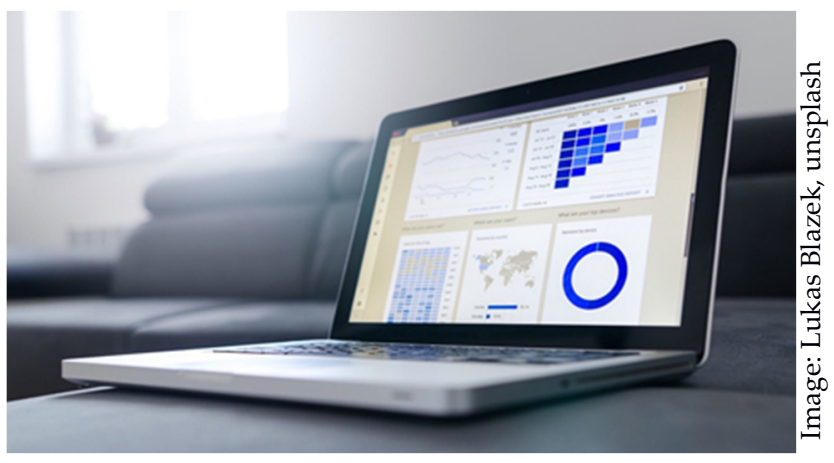

Computational models often suggest unambiguousness an expectation they do not always meet.

Another example is the integration of predictive toxicology, material flow analyses, and modelling of environmental behaviour into comprehensive modelling tools for nano risk governance. However, whilst computer models provide essential orientational knowledge, their application in policy advice implies specific challenges regarding their roles, authority, and effectiveness. Tensions may arise between expert knowledge and political negotiation, between realistic representations, necessary reductions or abstractions, and data availability and quality, and between scientific credibility, political relevance, and legitimacy.

\section{BASIC DATA}

$\begin{array}{ll}\text { Project title: } & \begin{array}{l}\text { Computational Modelling in Policy } \\ \text { Advice (CoMoPA) }\end{array} \\ \text { Project team: } & \begin{array}{l}\text { Bauer, A., Capari, L., Fuchs, D., } \\ \text { Udrea, T. }\end{array} \\ \text { Duration: } & \begin{array}{l}\text { O6/2018 }-08 / 2020 \\ \text { Funded by: }\end{array} \\ & \begin{array}{l}\text { Innovation fund of the Austrian } \\ \text { Academy of Sciences }\end{array}\end{array}$




\section{KEY RESULTS}

The project "Computational modelling in policy advice" (CoMoPA) conducted case studies on the various roles of computer models in policy advice in three areas: energy transition, European Union (EU) free trade agreements, and nano risk governance. Energy system modelling has increasingly become embedded in the climate change discourse and informs long-term strategies for decarbonisation at national and regional levels. Modelling of multilateral trade relations shows the relevance of involving a variety of stakeholders. If specific stakeholders feel underrepresented, they might contest the results, as the controversies surrounding the Transatlantic Trade and Investment Partnership (TTIP) agreement suggest.

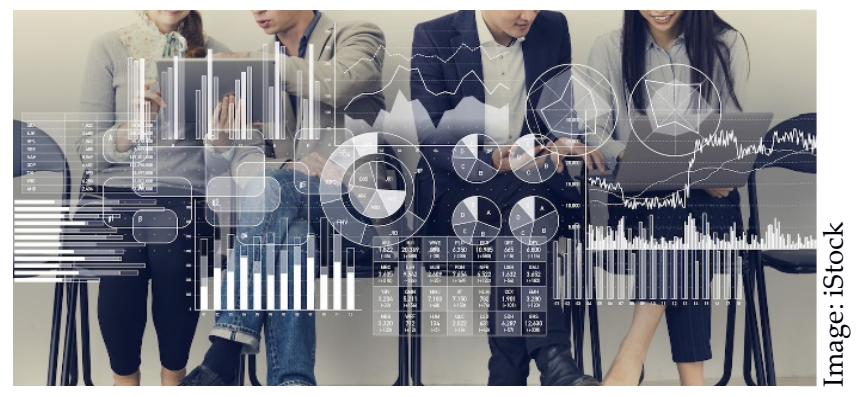

Computational modelling can enable fruitful discussions - both as subject and trigger of the debate.

Furthermore, authority and acceptance of models are essential. Transparency regarding model assumptions, processes, and results is a crucial aspect. When a broad range of scientific disciplines and societal actors is considered, modelling may become more salient and robust. This not only ensures scientific reliability but also facilitates more legitimate results. Through broad participation, models contribute to concretising debates and making them more purposeful, in short: they assist in spanning boundaries between different areas of society. Simultaneously, the growing complexity of models may hamper transparency as they become incomprehensible, especially to non-modellers. In science, a lack of transparency complicates model validation, comparability, and reproducibility. In the case study on nano risks, this was closely related to the availability of valid data (sets). In politics, a lack of transparency can undermine the models' legitimacy, especially when potentially controversial model assumptions or incomplete data sets are not sufficiently disclosed or discussed.

\section{WHAT TO DO?}

Computer models are no simple representation of reality but multi-layered compounds of (technical, political, and scientific) assumptions, simplifications, interests, and perpetuations of established thought patterns. As a result, transparency regarding model architecture, underlying calculations, model assumptions, and reliability of the data in use is essential. Moreover, attention should be paid to the positioning of models within policy processes (e.g. are they part of political negotiations, stakeholder processes for strategy development or evidence-based policy implementation). Consequently, different requirements need to be integrated:

- Transparency and openness during the modelling process: The negotiations to which models are subject to should be open and transparent. Assumptions, validity, and limitations of computational modelling should be continuously reflected and communicated in the respective advisory and policy contexts (between science and politics, and beyond these areas, particularly if there is strong public interest).

- Use of models to actively share knowledge and enhance understanding between actors: When focusing on modelling as a process, models are useful for promoting a mutual understanding of different areas of expertise, ideas, interests, and goals of various actors in society.

- Quality assurance: Clear procedures for scientific quality assurance increase credibility, especially for models that are policy-oriented.

\section{FURTHER READING}

Bauer, A. (2018). Politik(beratung) aus dem Computer. Gastkommentar. APA Science-Dossier 'Die Simulierte Forschung'. science.apa.at/dossier/Politikbertung aus dem Computer/SCI 20180628 SCI79155173843097922

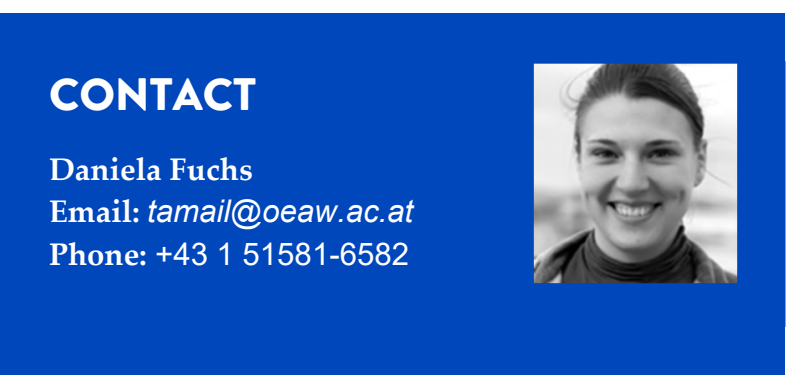

